\title{
Perencanaan Sistem Drainase di Kawasan Sungai Anak Jaya Setia 1 Kabupaten Bungo Provinsi Jambi
}

\author{
Ade Kurnia Putri ${ }^{1}$, Junaidi ${ }^{2}$, Bambang Istijono ${ }^{3}$ \\ ${ }^{1}$ Teknik Sipil Universitas Muara Bungo \\ ${ }^{2,3}$ Teknik Sipil Universitas Andalas \\ Email Korespondensi : *adekurniaputri245@gmail.com, ${ }^{2}$ junaidi.joe@gmail.com ${ }^{3}$ bistijono1452@yahoo.com
}

\begin{abstract}
Abstrak. Sungai Anak Jaya Setia 1 yang terletak di Kabupaten Bungo sering mengalami banjir. Saluran drainase yang ada masih berupa saluran drainase alami. Tujuan utama dalam penelitian ini adalah menganalisa perhitungan saluran drainase di daerah Sungai Anak Jaya Setia 1 dengan debit banjir rencana 5 tahun untuk saluran sekunder, merencanakan Storage sebagai pembuangan akhir dari saluran drainase, Membandingkan menggunakan Storage sebagai membuangan akhir dan tanpa Stoarge. Data-data yang digunakan pada penelitian ini adalah peta tata guna lahan untuk penentuan persentase impervious area, data hujan. Seri data hujan yang digunakan merupakan data hujan jam-jaman. Maka dari itu perlunya melakukan modifikasi pada data curah hujan, penentuan distribusi hujan jam-jaman dilakukan dengan mengubah lengkung Intensitas-Durasi-Frekuensi (IDF) untuk periode ulang 5 tahun menjadi hyetograph hujan rencana dengan menggunakan Alternating Block Method (ABM). Setelah semua parameter input EPA SWMM 5.1 ditentukan dan diinputkan sehingga simulasi dapat dilakukan. Kualitas simulasi cukup baik apabila continuity error untuk limpasan permukaan dan penelusuran aliran $<10 \%$. Simulasi yang dilakukan pada penelitian ini dibagi menjadi 2 skenario. Dari 2 skenario yang dilakukan jumlah titik banjir pada skenario 1 berjumlah 4 titik yang berada pada Junc 4, Junc 11, Junc 15 dan Junc 16. Sedangkan pada skenario 2 dengan di tambakannya Storage sebagai tempat penampungan air sementara sebelum di alirkan ke Outall terdapat 2 titik banjir yaitu pada Junc 12 dan Storage 2. Hal ini menunjukkan bahwa menambahkan storage sebagai tempat pembuangan cukup membantu mengurangi titik banjir.
\end{abstract}

Kata kunci: Banjir, Impervious Area, Jaringan Drainase, Alternating Blocking Method, EPA SWMM 5.1

\section{PENDAHULUAN}

Pertumbuhan kota menimbulkan dampak yang cukup besar pada siklus hidrologi, sehingga berpengaruh besar terhadap sistem drainase perkotaan. Sungai Anak Jaya Setia 1 yang terletak di Kabupaten Bungo sering mengalami banjir dan genangan pada saat intensitas curah hujan tinggi. Saluran drainase yang ada masih belum mampu menampung air hujan dikarenakan pembuangan akhir untuk air hujan masih belum ada dan saluran drainase yang ada berupa saluran drainase alami sehingga bila terjadi curah hujan yang besar saluran ini belum dapat menampung seluruh debit yang ada, yang mana air yang ada pada saluran akan melimpah dan terjadi genangan air pada jalan dan pemukiman rumah warga.

Penelitian ini bertujuan untuk merencanakan sistem saluran drainase di daerah Sungai Anak Jaya Setia 1 dengan debit banjir rencana 5 tahun untuk saluran sekunder, dengan menggunakan dua skenario yaitu : tanpa storage dan dengan storage sebagai tempat penyimpanan sementara sebelum dialirkan ke outfall.

Manfaat penelitian ini adalah untuk memberikan informasi kepada pemerintah terkait dan pihak PUPR Bidang Cipta Karya dan BAPPEDA Kabupaten Bungo mengenai saluran drainase yang baik untuk kawasan Sungai Anak Jaya Setia 1 Kabupaten Bungo Provinsi Jambi dengan data lapangan dan data perencanaan.

Batasan masalah yang di bahas dalam penelitian ini adalah bagaimana cara mengatasi banjir yang sering terjadi di kawasan Sungai Anak Jaya Setia 1 dengan melakukan Evaluasi dengan menggunakan Software EPA SWMM pada saluran dan Polder (Storage Unit). 


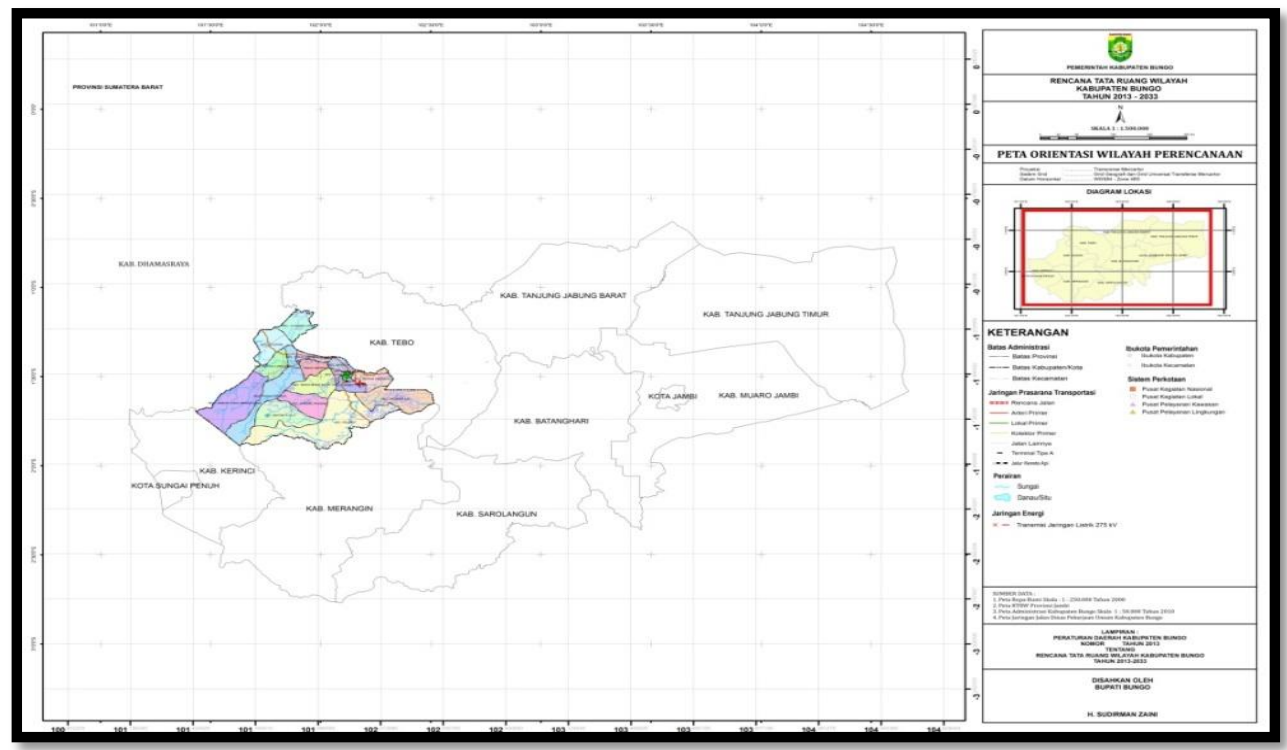

Gambar 1. Peta Lokasi Penelitian

Sumber : Bappeda Kabupaten Bungo,2013

1. Menggunakan peta tata guna lahan tahun 2019 yang didigitasi menggunakan Google Eart dan saluran drainase yang di rencanakan pada jaringan drainase daerah kawasan Sungai Anak Jaya Setia 1 hanya saluran sekunder pada kawasan Pelabuhan baru dan saluran Primer pada Jl. Jaya Setia.

2. Simulasi dilakukan dengan menggunakan EPA SWMM 5.1.

3. Merencanakan Polder (Storage Units)

\section{METODE}

Proses penelitian ini dilakukan dalam tiga bagian yakni pengumpulan data, pengolahan data dan hasil penelitian berupa kesimpulan dan saran. Prosedur pada penelitian ini tergambar dalam diagram alir (flowchart) di bawah ini :

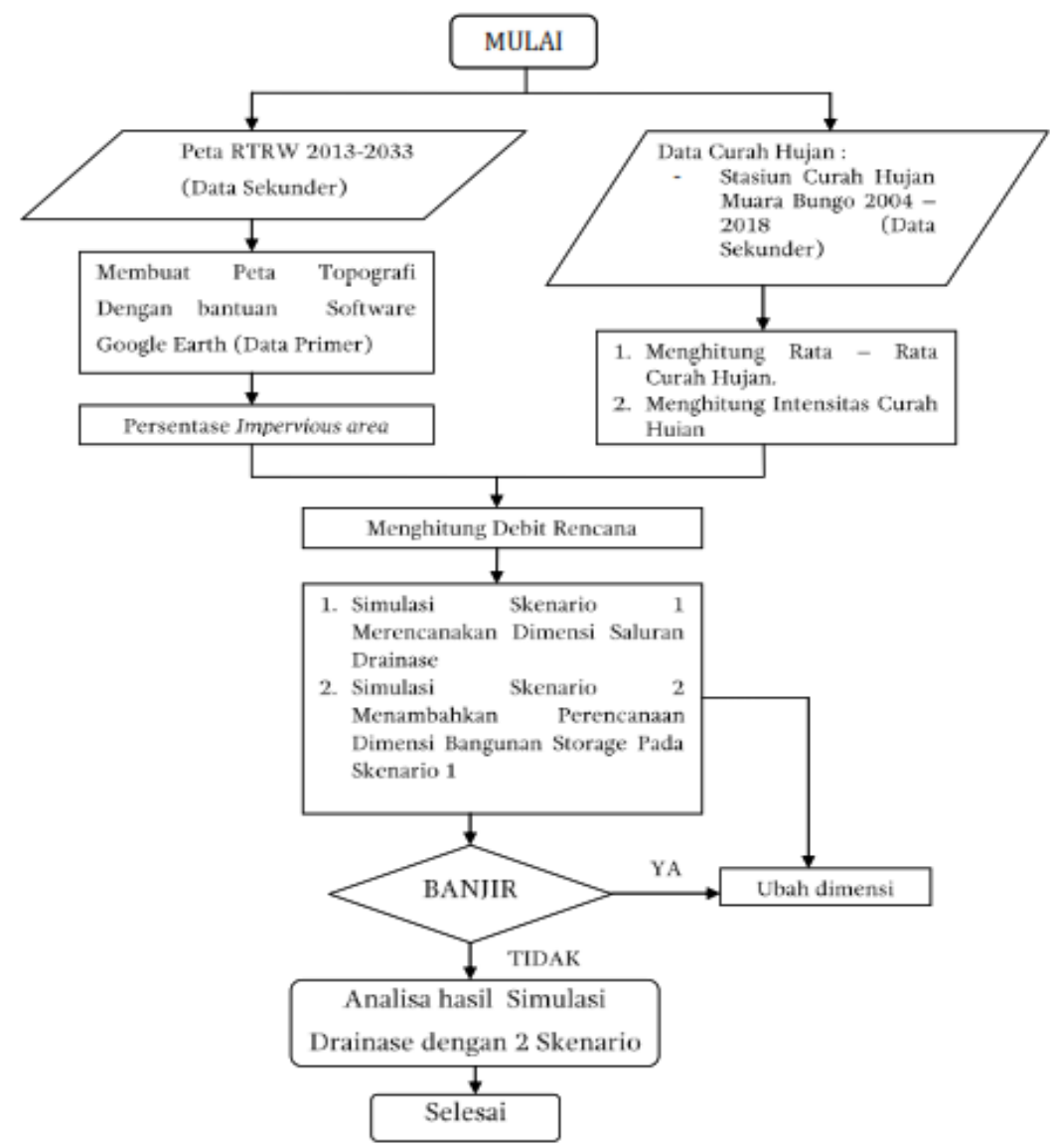

Gambar 2. Diagram Alir Penelitian 


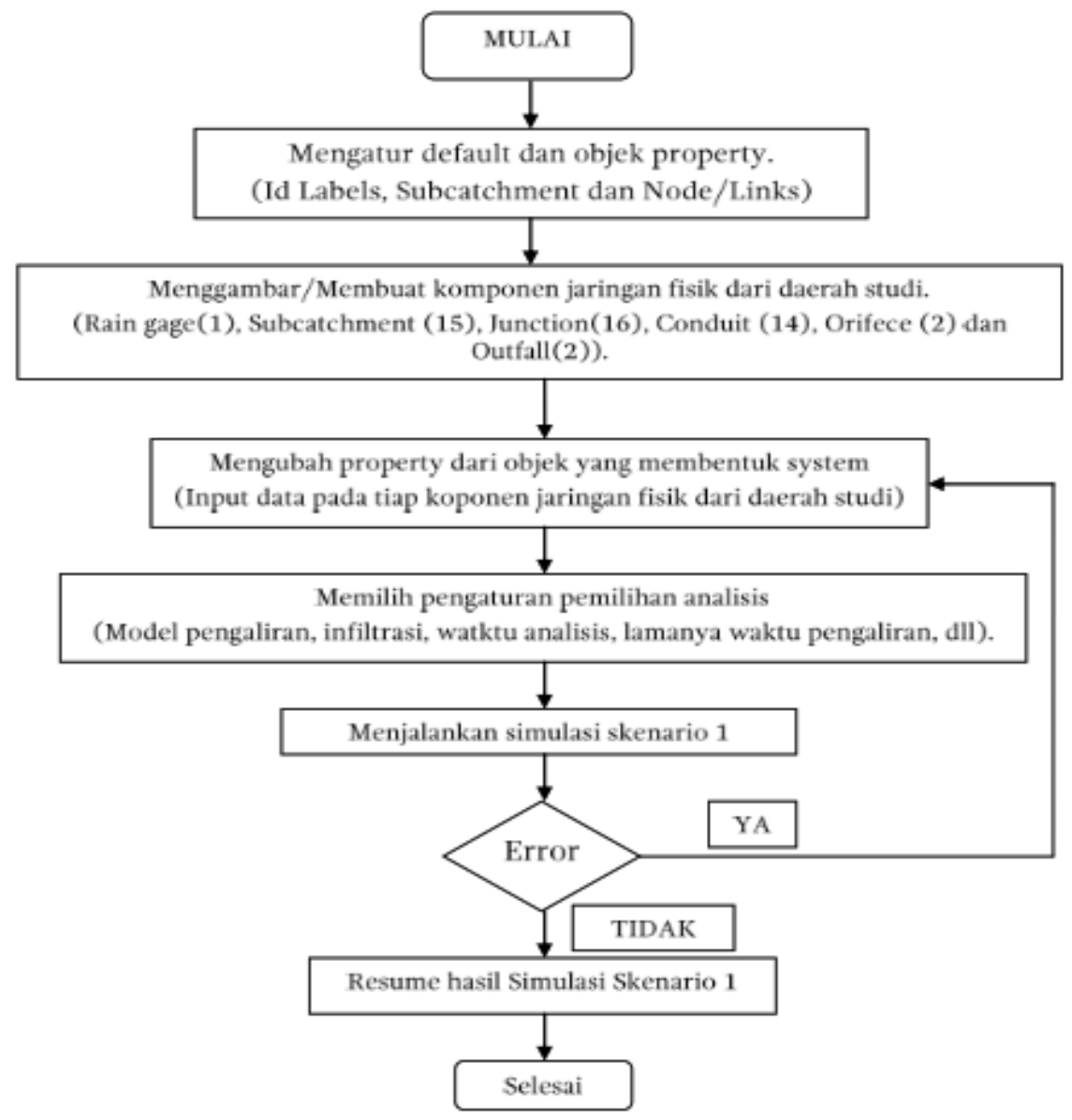

Gambar 3. Diagarm Alir Epa SWMM 5.1 pada Skenario 1

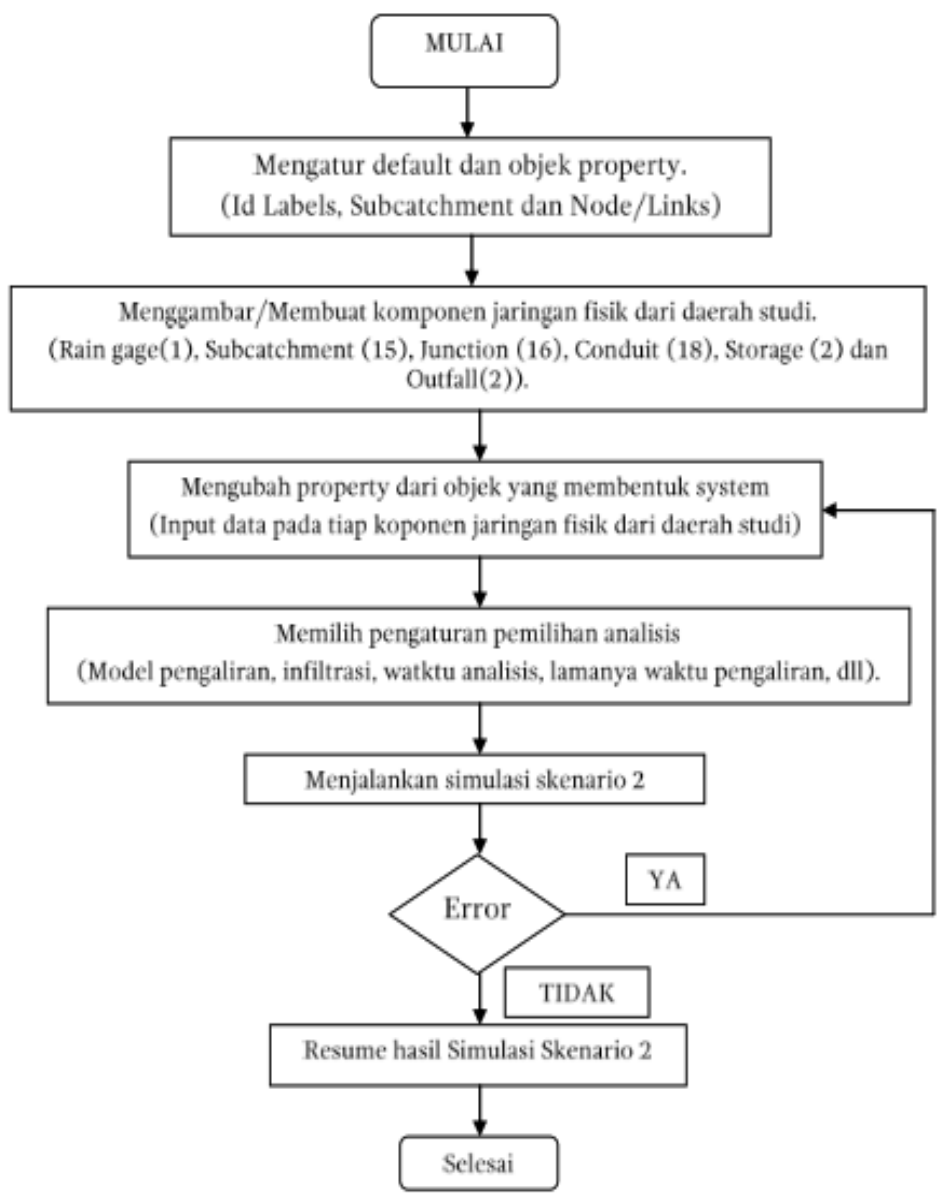

Gambar 4. Diagarm Alir Epa SWMM 5.1 pada Skenario 2 


\section{HASIL PEMBAHASAN}

Impervious

Impervious adalah persentase luas dari daerah yang kedap air dari suatu subcatchment, tidak dapat menyerap air, seperti jalan beraspal, rumah tinggal, perkantoran, pabrik dan pertokoan. Dalam penelitian ini, persentase dihitung dengan mengurangi luas area suatu subcatchment dengan luas daerah yang terlihat masih hijau pada Google Earth Pro. Selanjutnya untuk menentukan luasan kawasan juga menggunakan Google Earth Pro dapat dilihat pada gambar 4.

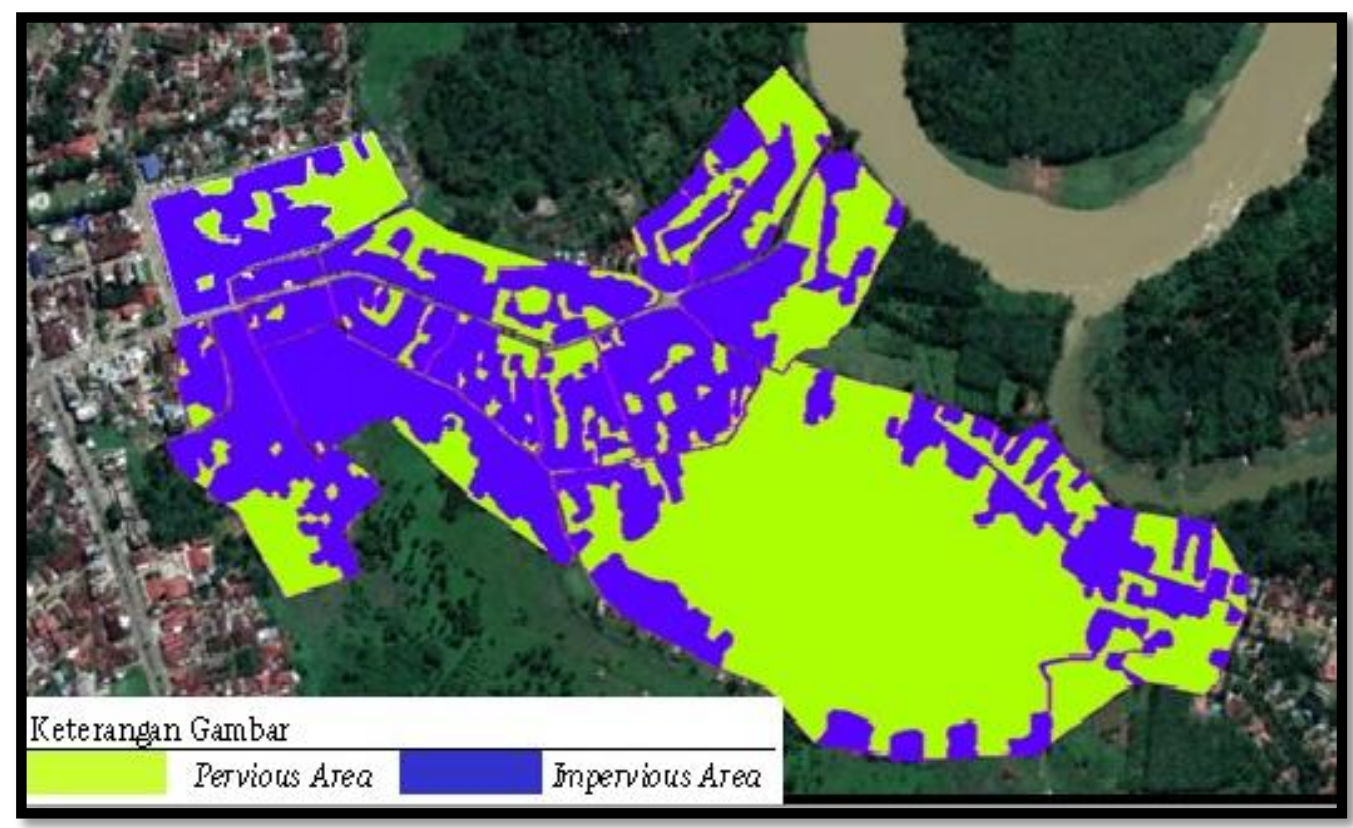

Gambar 5. Persentase impervious area kawasan Sungai Anak Jaya Setia 1 Mengguanakan Google Eart Pro pada tahun 2019 Sumber : Software Google Eart Pro

Tabel 1. Persentase impervious area kawasan Sungai Anak Jaya Setia 1 kondisi existing hasil Menggunakan Google Earth dan Pengamatan Lapangan

\begin{tabular}{ccccccc}
\hline No & D TA & $\begin{array}{c}\text { Luas A real } \\
\text { (H a) }\end{array}$ & $\begin{array}{c}\text { Luas Saw ah } \\
\text { (pervious area) } \\
(\text { H a) }\end{array}$ & $\begin{array}{c}\text { Luas Perum ahan } \\
\text { (im pervious area) }\end{array}$ & $\begin{array}{c}\text { Pervious } \\
\text { A rea } \\
(\mathrm{H} \mathrm{a})\end{array}$ & $\begin{array}{c}\text { Im pervious } \\
\text { A rea (kedap) }\end{array}$ \\
\hline 1 & SPB1 & 3,78 & 1,3 & 2,48 & 34,39 & 65,61 \\
2 & SPB2 & 0,34 & 0,01 & 0,33 & 3,53 & 96,47 \\
3 & SPB3 & 3,41 & 1,5 & 1,91 & 43,99 & 56,01 \\
4 & SPB4 & 1,68 & 0,61 & 1,07 & 36,31 & 63,69 \\
5 & SPB5 & 1,81 & 0,99 & 0,82 & 54,7 & 45,3 \\
6 & SUS1 & 0,64 & 0,28 & 0,36 & 43,44 & 56,56 \\
7 & SUS2 & 3,97 & 1,19 & 2,78 & 29,97 & 70,03 \\
8 & SUS3 & 0,56 & 0,04 & 0,52 & 7,14 & 92,86 \\
9 & SUS4 & 1,16 & 0,24 & 0,92 & 20,69 & 79,31 \\
10 & SUS5 & 1,35 & 0,33 & 1,02 & 24,53 & 75,47 \\
11 & SUS6 & 3,97 & 0,52 & 3,45 & 13,1 & 86,9 \\
12 & SUS7 & 1,48 & 0,65 & 0,83 & 43,92 & 56,08 \\
13 & SUS8 & 2,6 & 2,54 & 0,06 & 97,69 & 2,31 \\
14 & SUS9 & 27,2 & 20,99 & 6,21 & 77,17 & 22,83 \\
15 & SUS10 & 3,76 & 1,98 & 1,78 & 52,66 & 47,34 \\
\hline
\end{tabular}

Sumber : Google Earth dan Pengamatan Lapangan, Juli 2020

Keterangan :

SPB dan SJS = Subcatchment $($ Sub daerah tangkapan air $)$ 


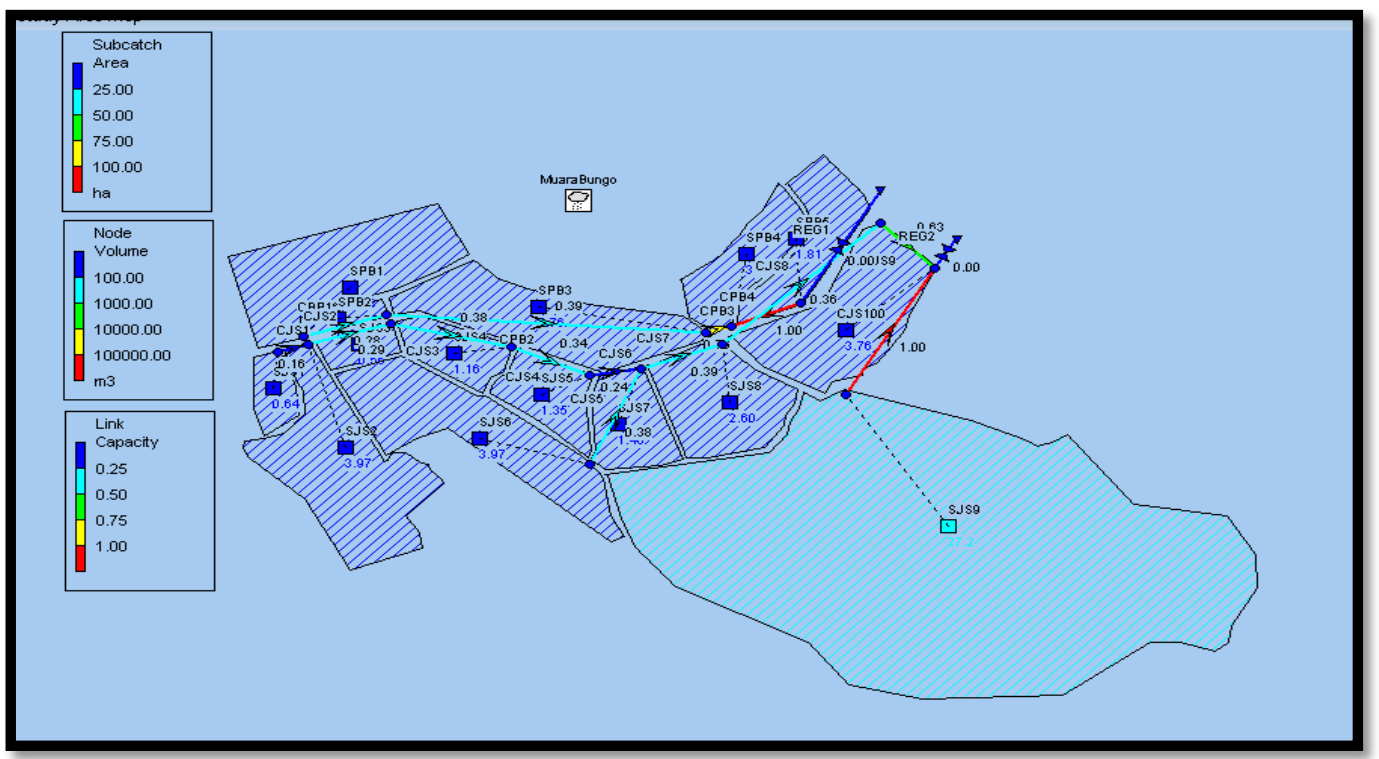

Gambar 6. Persentase impervious area kawasan Sungai Anak Jaya Setia 1 Kabupaten Bungo, 2020 Sumber :Software Epa SWMM 5.1

Jaringan Drainase Link

Dalam penelitian ini, terdapat 2 tipe link yang digunakan yaitu Conduit dan Outlet. simbol saluran dalam EPA SWMM dilambangkan dengan huruf C (Coinduit).

Tabel 2. Nilai Karakteristik Link

\begin{tabular}{|c|c|c|c|c|c|}
\hline \multirow[b]{2}{*}{$\mathbf{N}$ am a } & \multirow[b]{2}{*}{ Tipe } & \multirow[b]{2}{*}{ Inlet } & \multirow[b]{2}{*}{ O tlet } & \multicolumn{2}{|c|}{$\begin{array}{c}\text { Perencanaan } \\
\text { D im ensiSahuran }\end{array}$} \\
\hline & & & & $\begin{array}{c}b \\
\text { (m) }\end{array}$ & (m) \\
\hline \multicolumn{6}{|c|}{ SA LURAN SEKUN DER PELABUH AN BARU } \\
\hline CPB1 & Sahuran terbuka & $\mathrm{UN} \mathrm{C} 1$ & $\mathrm{UN} \mathrm{C} 2$ & 1,8 & 2 \\
\hline C PB2 & Sahuran terbuka & $\mathrm{U} \mathrm{N} \mathrm{C2}$ & $\mathrm{UN} \mathrm{C} 3$ & 2,2 & 2 \\
\hline C PB 3 & Sahuran terbuka & $\mathrm{U} \mathrm{N} \mathrm{C} 3$ & $\mathrm{U} \mathrm{N} \mathrm{C} 4$ & 1,8 & 2 \\
\hline C PB 4 & Sahuran terbuka & $\mathrm{U} \mathrm{N} \mathrm{C} 4$ & $\mathrm{UN} \mathrm{C} 5$ & 1,8 & 2 \\
\hline REG 1 & Pintu $A$ ir & $\mathrm{U} N \mathrm{C} 5$ & OUT1 & 1 & 1 \\
\hline \multicolumn{6}{|c|}{ SA LURAN PR IM ER U. JAYA SET IA } \\
\hline $\mathrm{CJS1}$ & Sahuran terbuka & $\mathrm{UN} \mathrm{C} 6$ & $\mathrm{UN} \mathrm{C7}$ & 1,8 & 2 \\
\hline $\mathrm{C} \sqrt{ } 2$ & Sahuran terbuka & $\mathrm{U} \mathrm{N} \mathrm{C} 7$ & $\mathrm{UN} \mathrm{C} 8$ & 1,8 & 2 \\
\hline $\mathrm{C} \sqrt{\mathrm{S} 3} 3$ & Saluran terbuka & $\mathrm{UN} \mathrm{C} 8$ & U N C 9 & 1,8 & 2 \\
\hline $\mathrm{CJS} 4$ & Saluran terbuka & U N C 9 & $\mathrm{UN} \mathrm{C} 10$ & 1,8 & 2 \\
\hline C $\sqrt{5} 5$ & Saluran terbuka & $\mathrm{UN} \mathrm{C} 11$ & $\mathrm{UN} \mathrm{C} 12$ & 1,8 & 2 \\
\hline $\mathrm{c} \operatorname{ss} 6$ & Sahuran terbuka & $\mathrm{UN} \mathrm{C} 10$ & $\mathrm{UN} \mathrm{C} 12$ & 1,8 & 2 \\
\hline $\mathrm{C} \sqrt{\mathrm{S} 7}$ & Sahuran terbuka & $\mathrm{U} \mathrm{N} \mathrm{C} 12$ & $\mathrm{UNC} 13$ & 1,8 & 2 \\
\hline $\mathrm{C} J \mathrm{~S} 8$ & Sahuran terbuka & $\mathrm{UNC} 13$ & U N C 14 & 2,2 & 2 \\
\hline $\operatorname{cus} 9$ & Sahuran terbuka & $\mathrm{U} \mathrm{N} \mathrm{C} 14$ & U N C 15 & 2,2 & 2 \\
\hline $\mathrm{C} J \mathrm{~S} 10$ & Sahuran terbuka & $\mathrm{UN} \mathrm{C} 15$ & $\mathrm{UNC} 16$ & 1,8 & 2 \\
\hline REG 2 & Pintu $A$ ir & $\mathrm{UN} \mathrm{C} 16$ & OU T2 & 1 & 1 \\
\hline
\end{tabular}

Sumber : Data Olahan (2020) 


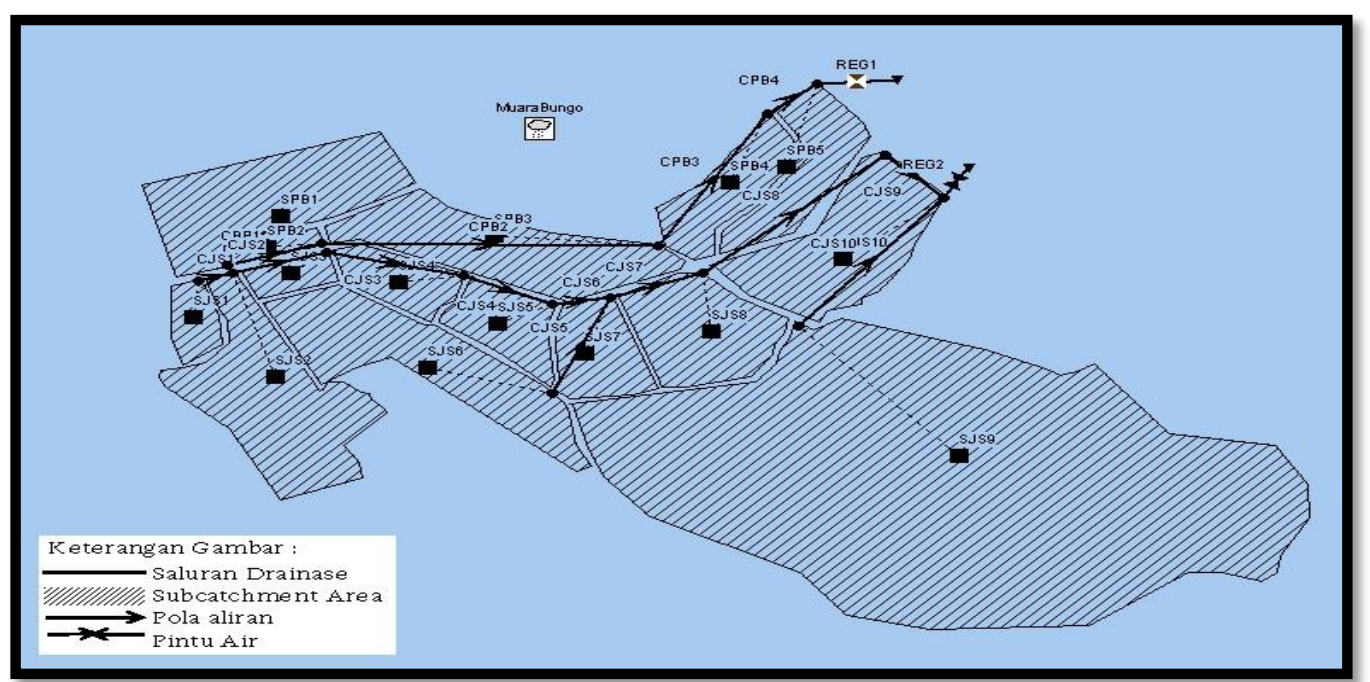

Sumber : Software Epa SWMM 5.1

Gambar 7. Posisi Conduit (Saluran Terbuka)

Node

Node merupakan tempat pertemuan inlet dan outlet yang juga sebagai tempat masuknya aliran permukaan dari subcatchment. Node yang dipakai dalam penelitian terdiri dari 16 junction dan 2 outfall. Dalam menentukan titik Bench Mark pada penelitian ini menggunakan GPS Garmin sedangkan untuk pengukuran node dan outfall digunakan Waterpass (Topcon at - b4a) Tabel 3 Nilai Karakteristik Node.

Tabel 3 Nilai karakteristik Elevasi Saluran

\begin{tabular}{|c|c|c|c|c|c|}
\hline $\mathrm{N}$ am a & Tipe & Elevasi & $\mathrm{N}$ am a & T pe & Elevasi \\
\hline $\mathrm{UN} \mathrm{C} 1$ & Junction & 60,80 & $\mathrm{UN} \mathrm{C} 10$ & Junction & 54,50 \\
\hline U N C 2 & Junction & 59,60 & U N C 11 & Junction & 53,00 \\
\hline $\mathrm{UNC} 3$ & Junction & 58,40 & $\mathrm{UN} \mathrm{C} 12$ & Junction & 51,50 \\
\hline U N C 4 & Junction & 57,20 & U N C 13 & Junction & 50,00 \\
\hline $\mathrm{UN}$ C 5 & Junction & 56,00 & U N C 14 & Junction & 48,50 \\
\hline U N C 6 & Junction & 60,50 & $\mathrm{UN} \mathrm{C} 15$ & Jun ction & 47,00 \\
\hline U N C 7 & Junction & 59,00 & $\mathrm{UN} \mathrm{C} 16$ & Junction & 45,50 \\
\hline $\mathrm{UN} \mathrm{C} 8$ & Junction & 57,50 & OUT1 & Outall & 54,80 \\
\hline $\mathrm{UNC} 9$ & Junction & 56,00 & OUT2 & O utall & 44,00 \\
\hline
\end{tabular}

Sumber : Data Olahan (2020)

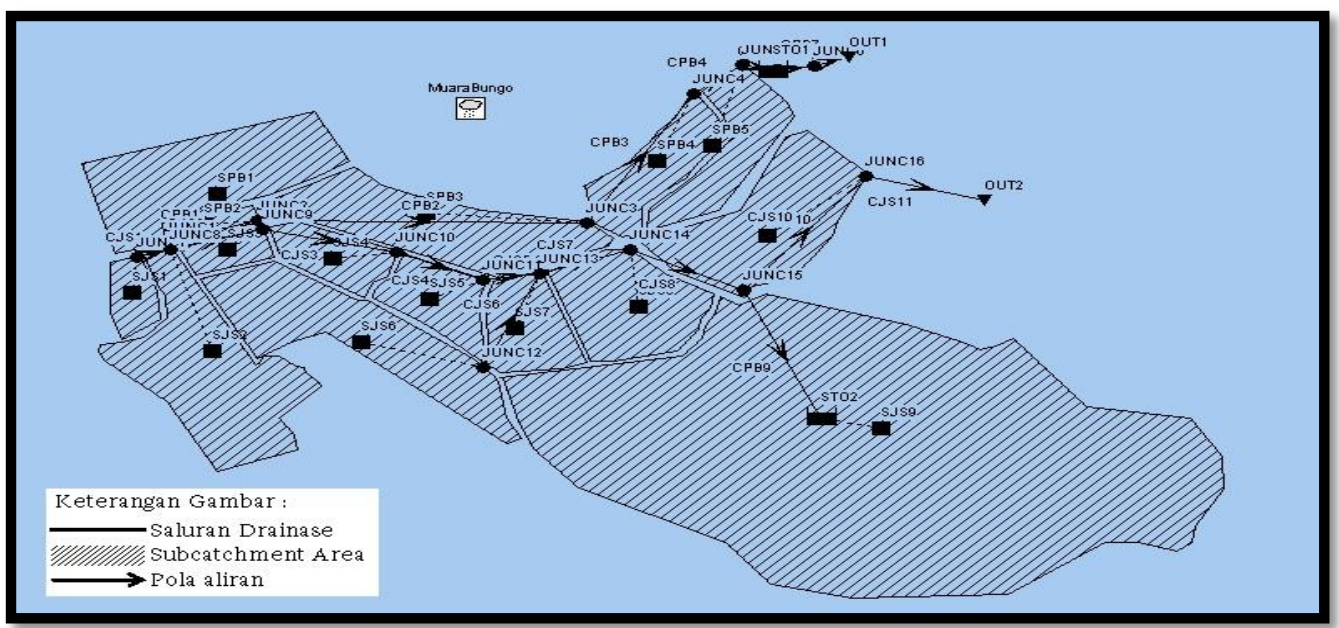

Sumber : Software Epa SWMM 5.1

Gambar 8. Posisi Junction dan Outfall 
Curah Hujan Rata - Rata

Data curah hujan dihitung menggunakan metode aritmatik. Hasil perhitungan curah hujan harian maksimum tersbut disajikan pada tabel 1 .

Tabel 4 curah hujan harian maksimum

\begin{tabular}{rccc}
\hline Tahun & Rata - Rata Curuah Hujan & Tahun & Rata - Rata Curuah Hujan \\
\hline 2004 & 419 & 2012 & 558 \\
2005 & 528 & 2013 & 510 \\
2006 & 478 & 2014 & 81 \\
2007 & 426 & 2015 & 46 \\
2008 & 389 & 2016 & 161 \\
2009 & 520 & 2017 & 385 \\
2010 & 393 & 2018 & 548
\end{tabular}

Sumber : Dinas Pertanian Kabupaten Bungo, (2019)

Analisis Frekuensi Curah Hujan

Di dalam penelitian ini untuk menganalisis Frekuensi Curah Hujan di gunakan dua Metode yaitu:

Tabel 7 Hasil Pengukuran Dispersi dan syarat distribusi yang digunakan

\begin{tabular}{|c|c|c|c|c|c|}
\hline No & Jenis Distribusi & Syarat & Hitungan & Keterangan & $\begin{array}{c}\text { Selisih } \\
(4-3)\end{array}$ \\
\hline 1 & 2 & 3 & 4 & 5 & 6 \\
\hline \multirow[t]{2}{*}{1} & Normal & $\mathrm{Cs} \approx 0$ & $-1,12$ & tidak memenuhi & $\overline{1,12}$ \\
\hline & & $\mathrm{Ck} \approx 3$ & 2,84 & tidak memenuhi & 0,16 \\
\hline \multirow[t]{2}{*}{2} & Normal-Log & $C s \approx C v^{3}+3 C v$ & $-1,9$ & tidak memenuhi & 2,29 \\
\hline & & $C k \approx C v^{8}+6 C v^{6}+15 C v^{4}+16 C v^{2}+3$ & 4,55 & tidak memenuhi & 1,27 \\
\hline \multirow[t]{2}{*}{3} & Gumbel & Cs $\approx 1.1394$ & $-1,12$ & tidak memenuhi & 2,26 \\
\hline & & $\mathrm{Ck} \approx 5.4$ & 2,84 & tidak memenuhi & 2,56 \\
\hline 4 & LP-III/Gama III-Log & Selain nilai di atas & & memenuhi & \\
\hline
\end{tabular}

Sumber : Data Olahan (2020)

Perhitungan Hyetograph Hujan Rancangan

Periode Ulang 5 Tahun

Hyetograph dalam bentuk mm merupakan perkalian dari persentase yang telah diurutkan dengan curah hujan.

Tabel 8 Perhitungan Periode Ulang 5 Tahun

\section{PERIODE ULANG 5 TAHUN}

\begin{tabular}{|c|c|c|c|c|c|c|c|}
\hline \multirow{2}{*}{ Td (jam) } & \multirow{2}{*}{$\Delta t(\mathbf{j a m})$} & \multirow{2}{*}{$\begin{array}{c}\text { It } \\
(\mathbf{m m} / \mathbf{j a m}\end{array}$} & \multirow{2}{*}{$\begin{array}{l}\text { It Td } \\
(\mathbf{m m})\end{array}$} & \multirow{2}{*}{$\Delta p(\mathbf{m m})$} & \multirow{2}{*}{ Pi (\%) } & \multicolumn{2}{|c|}{ Hyetograph } \\
\hline & & & & & & $(\%)$ & $(\mathbf{m m})$ \\
\hline 1 & 2 & 3 & 4 & 5 & 6 & 7 & 8 \\
\hline 1 & $0 \_1$ & 214,144 & 214,144 & 214,144 & 55,032 & 6,746 & 41,667 \\
\hline 2 & $1 \_2$ & 134,902 & 269,804 & 55,661 & 14,304 & 10,034 & 61,979 \\
\hline 3 & $2 \_3$ & 102,950 & 308,849 & 39,045 & 10,034 & 55,032 & 339,932 \\
\hline 4 & 3_4 & 84,983 & 339,932 & 31,083 & 7,988 & 14,304 & 88,356 \\
\hline 5 & $4 \_5$ & 73,236 & 366,181 & 26,249 & 6,746 & 7,988 & 49,342 \\
\hline 6 & $5 \_6$ & 64,854 & 389,125 & 22,944 & 5,896 & 5,896 & 36,422 \\
\hline \multicolumn{4}{|c|}{ Jumlah } & 389,125 & 100 & 100 & 617,698 \\
\hline
\end{tabular}

Sumber : Data Olahan (2020) 
Sumber : Data Olahan (2020)

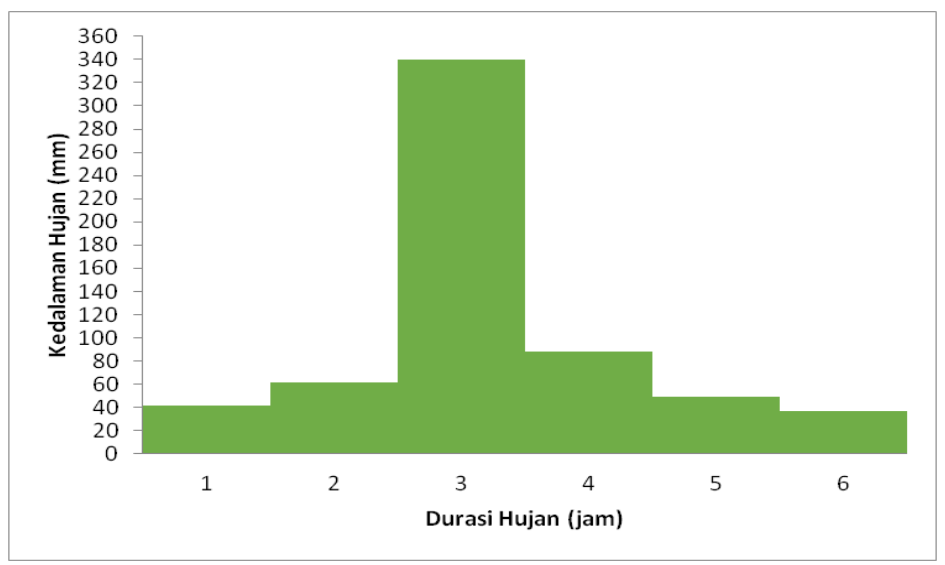

Gambar 9 Hyetograph hujan rencana

Hasil Pemodelan Jaringan Drainase Dengan EPA SWMM 5.1

Hasil Pemodelan jaringan drainase eksisting kawasan Sungai Anak Jaya Setia 1 dengan EPA SWMM 5.1 berdasarkan skenario yang dilakukan.

\section{Simulasi Skenario 1 Perencanakan Dimensi Saluran Drainase}

Dalam permodelan EPA SWMM 5.1 selanjutnya dilakukan simulasi, dimana yang akan diamati adalah kapasitas dari Saluran. Dari simulasi yang dilakukan didapat hasil kualitas simulasi yang cukup baik, dimana continuity error untuk limpasan permukaan dan penelusuran aliran sebesar $-0,48 \%$ dan $0,74 \%$. Menurut Rossman (2015) kualitas simulasi kurang baik jika continuity error $>10 \%$.

Dibawah ini adalah hasil simulasi pada Software SWMM pada Skenario 1 dalam durasi 4 jam untuk Jl. Pelabuhan Baru dan Jl. Jaya Setia

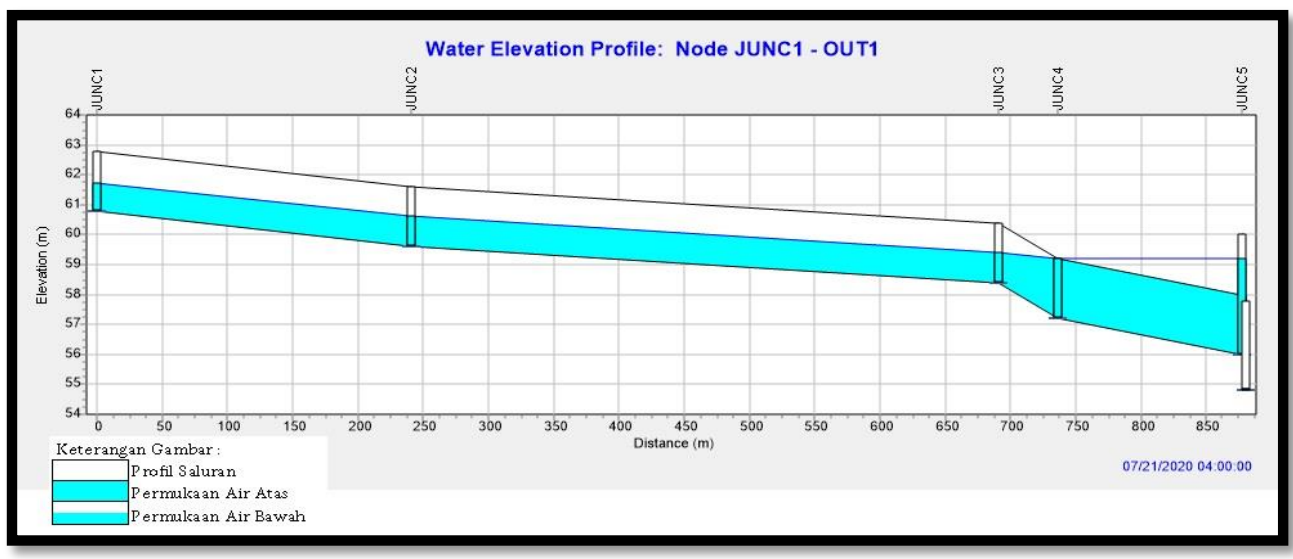

Gambar 10. Profil Aliran Saluran Sekunder Jl. Pelabuhan Baru Durasi Waktu 4 Jam Skenario 1 Sumber : Software Epa SWMM 5.1

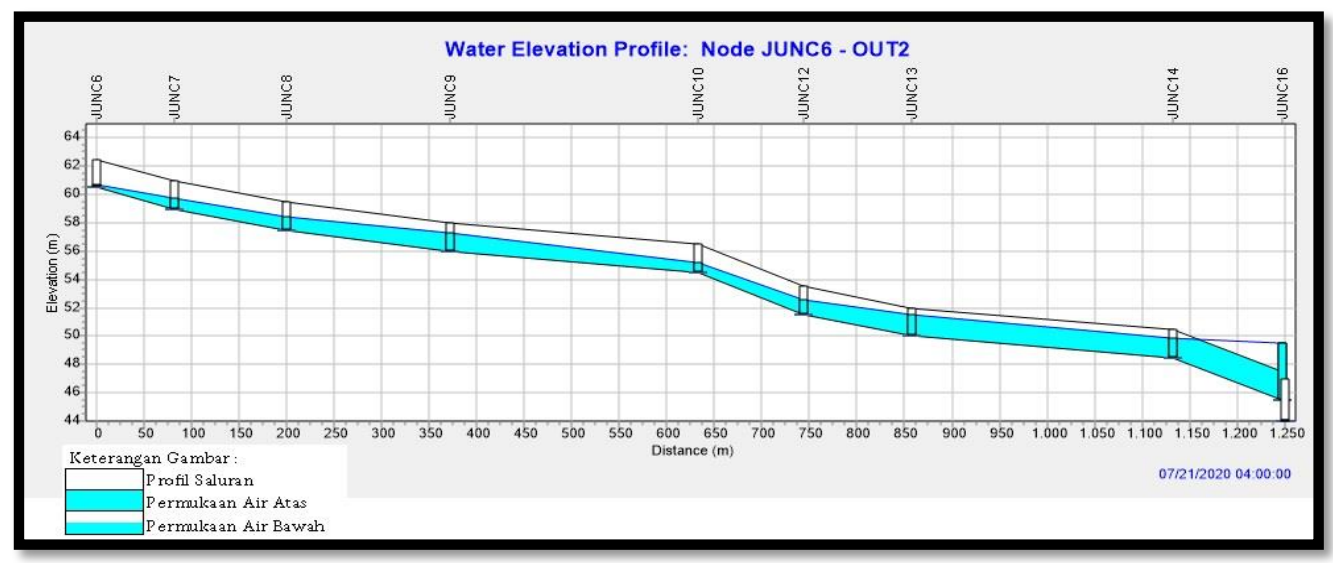

Gambar 11. Profil Aliran Saluran Sekunder Jl. Jaya Setia Durasi Waktu 4 Jam Skenario1 Sumber : Software Epa SWMM 5.1 


\section{Simulasi Model Skenario 2 (Menggunakan Storage Units)}

Selanjutnya didalam peneiitian ini dicoba simulasi menggunakan Storage yang didapat hasil dimana continuity error untuk limpasan permukaan dan penelusuran aliran sebesar $-0,48 \%$ dan $-0,42 \%$. Menurut Rossman (2004) jika kualitas simulasi mencapai angka 10\%, maka kualitas simulasi diragukan. Dengan demikian hasil simulasi yang didapat termasuk dalam kategori baik.

Link

Dalam penelitian ini, terdapat 2 tipe link yg digunakan yaitu conduit dan outlet. Pada Tabel 9 dibawah ini merupakan parameter-parameter data input pada properti dalam EPA SWMM 5.1.

Tabel 9. Nilai Karakteristik Storage

\begin{tabular}{lrr} 
& \multicolumn{3}{c}{ LuasA real D epth (Kedalam an ) } \\
\cline { 2 - 3 } & $\mathrm{H} \mathrm{a}$ & $\mathrm{m}$ \\
\hline STO 1 & 0,5 & 2 \\
STO2 & 1 & 3 \\
\hline
\end{tabular}

Sumber : Software Epa SWMM 5.1'

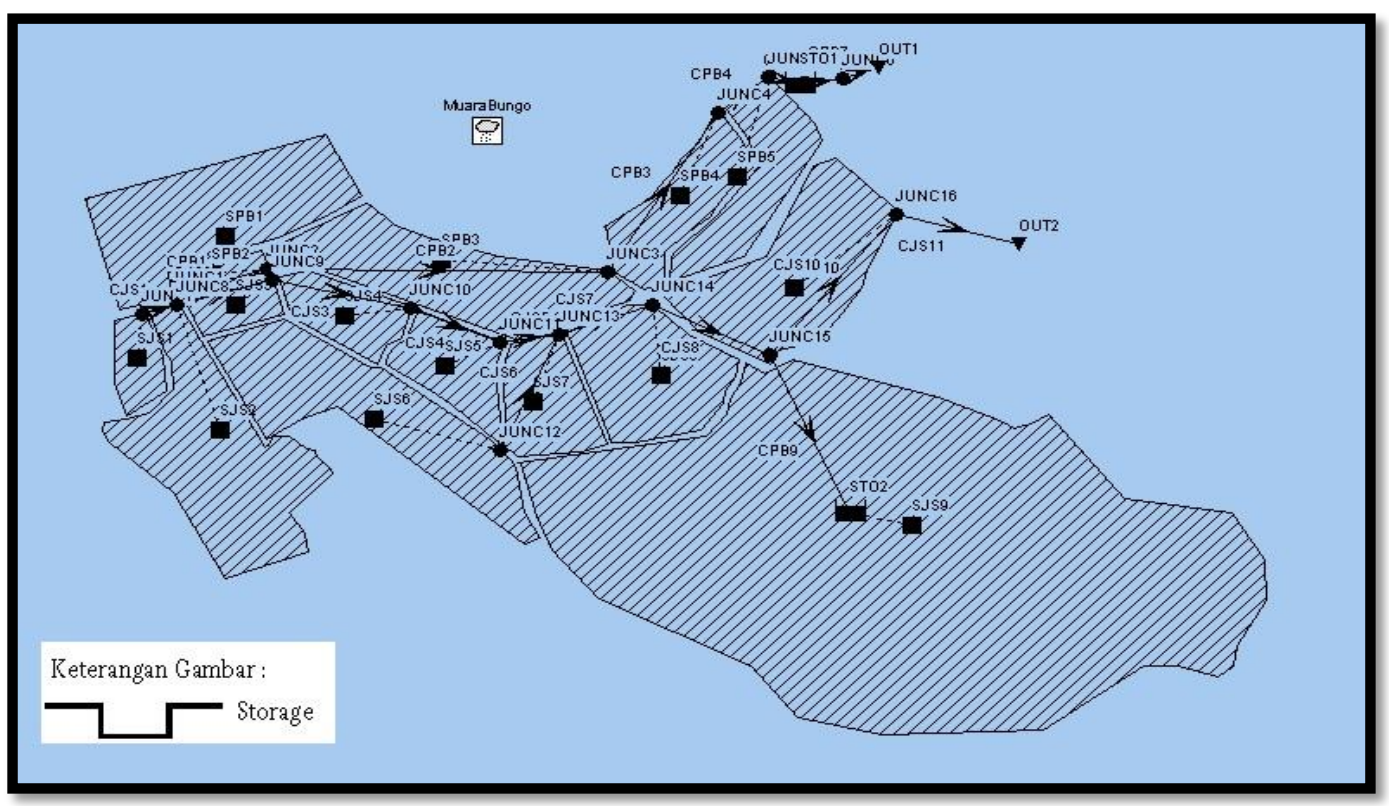

Gambar 12. Posisi Storage

Sumber : Software Epa SWMM 5.1

Curve STO1.

Pada aliran perencanaan ini akan di alirkan ke sungai Batang Tebo. Adapun berikutlah data untuk perencanaan

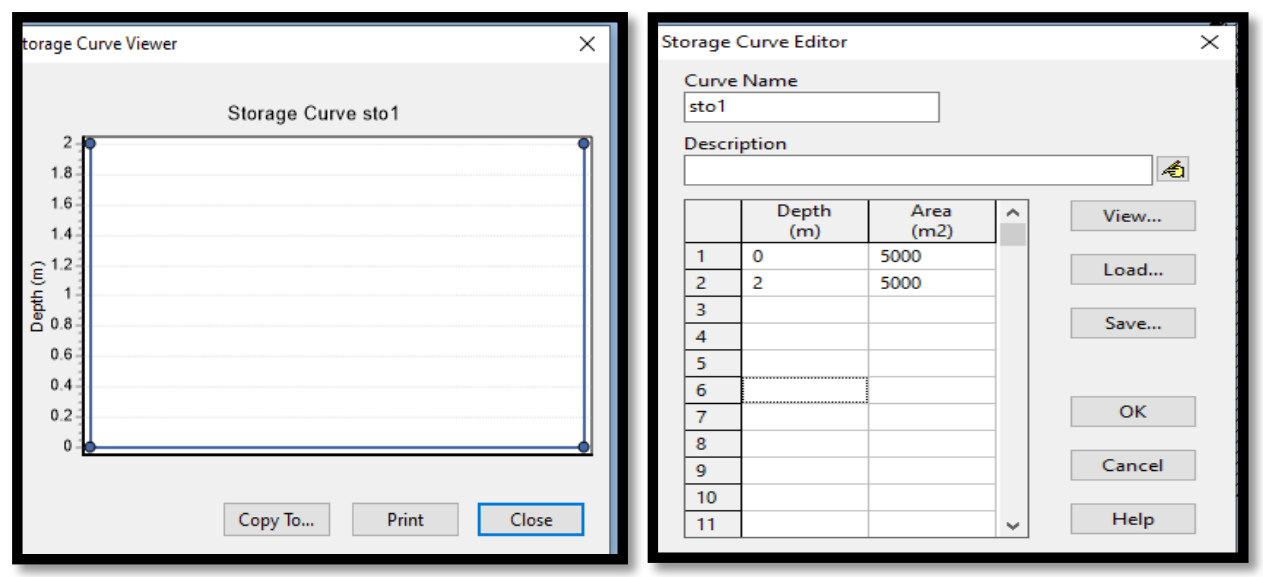

Gambar 13. STO1 curve Viewer dan Curve Editor ,2020

Sumber : Software Epa SWMM 5.1 
Dibawah ini adalah hasil simulasi pada Software SWMM pada Skenario 2 dalam durasi 4 jam untuk Jl. Pelabuhan Baru dan Jl. Jaya Setia.

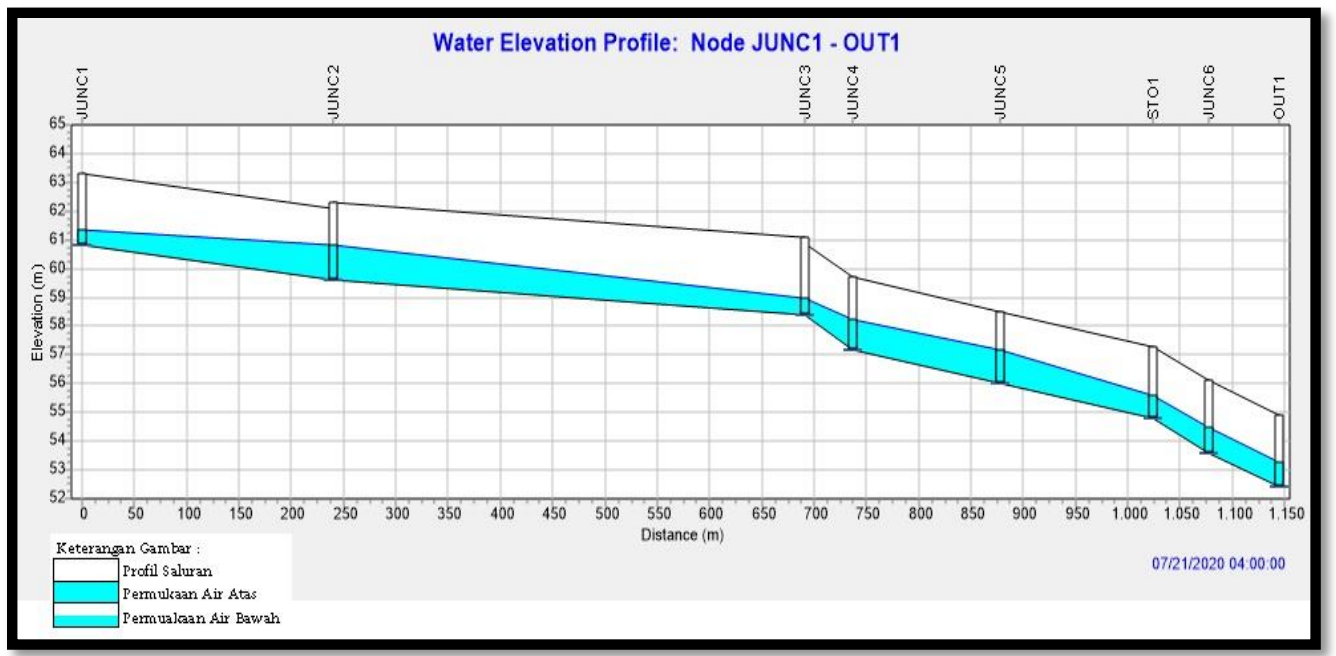

Gambar 14. Profil Aliran Saluran Sekunder Jl. Pelabuhan Baru Durasi Waktu 4 jam Skenario 2 Sumber : Software Epa SWMM 5.1

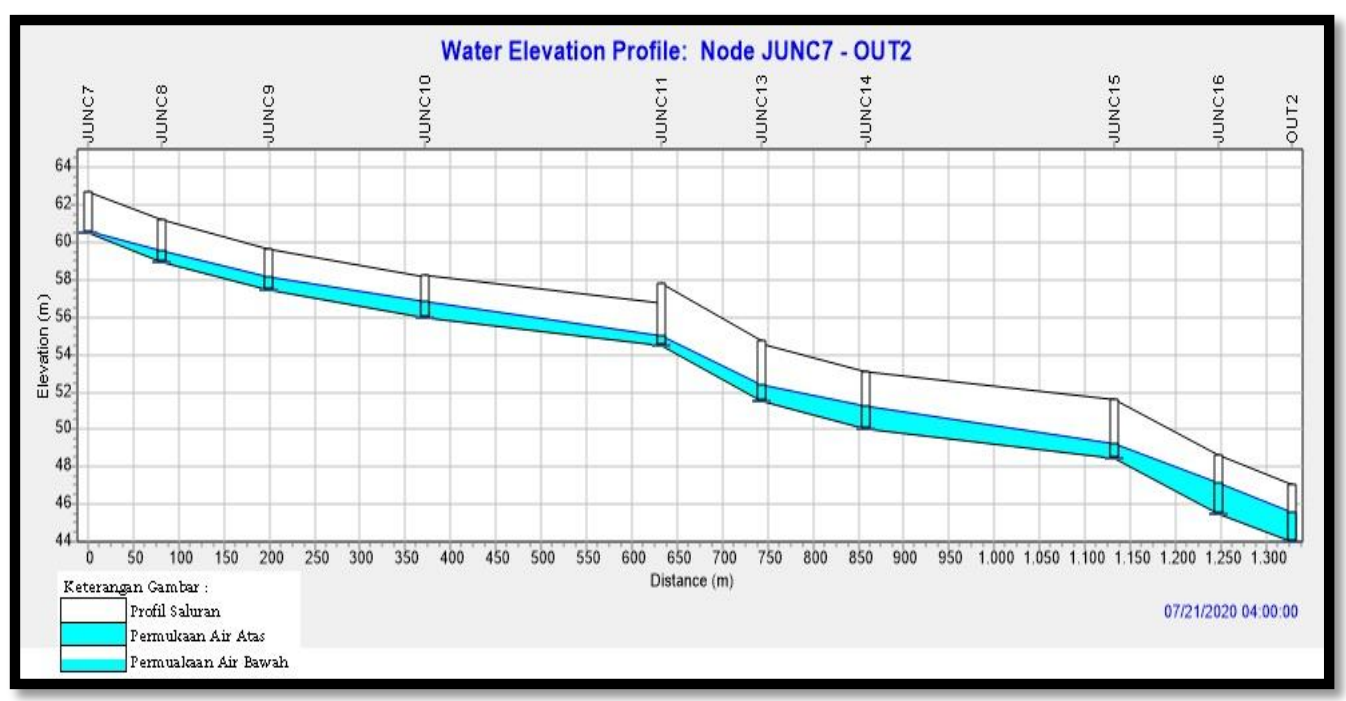

Gambar 15. Profil Aliran Saluran Sekunder Jl. Jaya Setia Durasi Waktu 4 jam Skenario 2 Sumber : Software Epa SWMM 5.1

Tabel 11 Perbandingan Lamanya Waktu Terjadi Banjir Dari 2 Skenario Penelitian

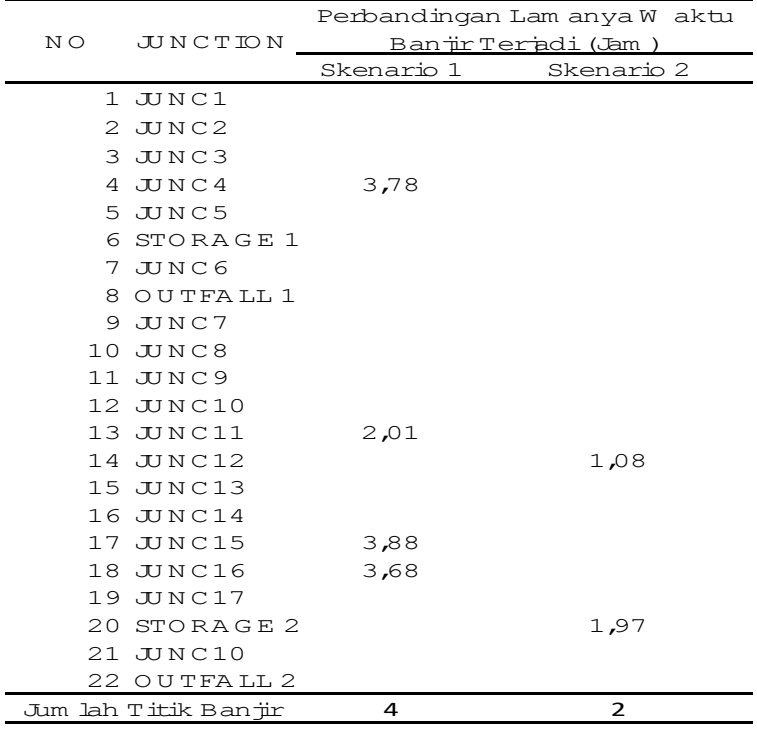

Sumber : Sorfware Epa SWMM 5.1 


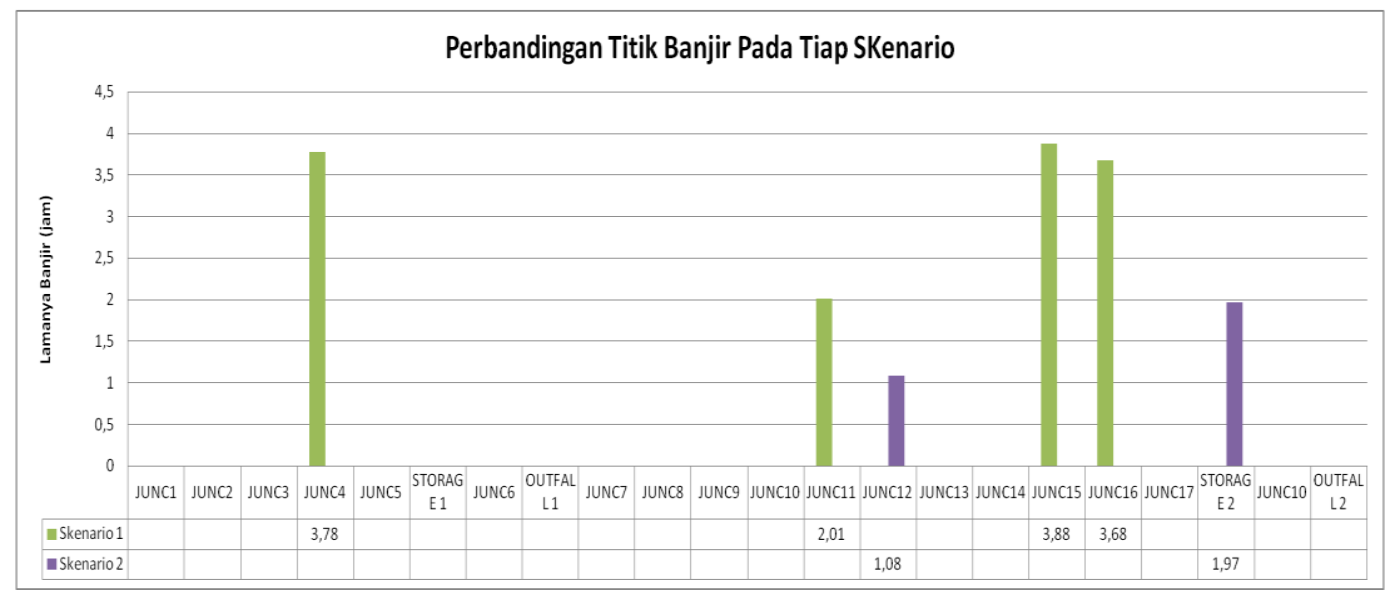

Gambar 16 Diagram Perbandingan Jumlah Titik - Titik Banjir Hasil Simulasi EPA SWMM. 5.1

\section{SIMPULAN}

Dari hasil penelitian Perencanaan Sistem Drainase Di Kawasan Sungai Anak Jaya Setia 1 Untuk Pengendalian Banjir Menggunakan Program Epa SWMM Versi 5.1. dapat disimpulkan bahwa :

1. Hasil simulasi menggunakan Epa SWMM 5.1 Saluran drainase tanpa Storage pada saluran pembuangan akhir di Kawasan Sungai Anak Jaya Setia 1 Mengakibatkan banjir pada 4 lokasi yaitu Junc 4, Junc 11, Junc 15 dan Junc 16.

2. Setelah dilakukan simulasi dengan menambahkan storage pada perencanaan saluran drainase sebelum dialirkan ke outfall ternyata cukup mampu mengatasi banjir. hanya terdapat 2 lokasi banjir yaitu pada Junc12 dan Storage 2 .

3. Kawasan Sungai Anak Jaya Setia 1 berada lebih rendah dari sungai, maka dari itu Storage dianggap perlu agar dapat mengurangi resiko banjir agar air tidak meluap ke permukiman rumah warga.

\section{Saran}

Saran yang dapat penulis usulkan adalah:

1. Penelitian ini dapat dilanjutkan dengan mengetahui data Pasang Surut Pada Sungai Batang Tebo.

2. Normalisasi Sungai Batang Tebo untuk mengurangi titik-titik banjir yang terjadi dapat dipertimbangkan pada penelitian selanjutnya.

\section{DAFTAR PUSTAKA}

Bappeda Kabupaten Bungo (2013), Peta Drainase Ok Kabupaten Bungo.

Rossman, Lewis A.; Environmental Scientist Emeritus. (2015). Storm Water Management Model User's Manual Version 5.1. United States: U.S. Environmental Protection Agnecy.

Dinas Pertanian Kabupaten Bungo (2019), Data Curah Hujan.

Menteri Pekerjaan Umum Republik Indonesia. (2014). Peraturan Menteri Pekerjaan Umum Republik Indonesia Nomor 12/PRT/M/2014. Indonesia: Kementerian Pekerjaan Umum.

Dinas Pekerjaan Umum dan Penataan Ruang (2019), DED (Detail Engineering Desain) Drainase Sungai Udo

Ade Kurnia Puri (2015), Perencanaan Saluran Drainase Di Kawasan Perumahaan Jaya Setia (Tugas Akhir). Padang, Universitas Bung Hatta. 